Check for updates

Cite this: Mater. Adv., 2021, 2, 3031

Received 7th February 2021 Accepted 20th March 2021

DOI: $10.1039 / \mathrm{d} 1 \mathrm{ma} 00115 a$

rsc.li/materials-advances

\title{
Protective interlayer for trapping polysulfides and a conducting host for sulfur: dual role of candle soot carbon for the development of high performance lithium-sulfur batteries $\dagger$
}

\author{
Vikram K. Bharti, Ananya Gangadharan, S. Krishna Kumar, Anil D. Pathak and \\ Chandra S. Sharma (DD*
}

\begin{abstract}
The commercial realization of next-generation lithium-sulfur ( $\mathrm{Li}-\mathrm{S}$ ) batteries is mainly hindered due to the unwanted lithium polysulfide shuttling and the insulating nature of the sulfur cathode. In the present work, we aim to overcome these critical challenges by the first-time usage of candle soot carbon as a conducting host as well as an inbuilt interlayer. The Li-S battery thus fabricated delivers an impressive capacity of $1182 \mathrm{~mA} \mathrm{~h} \mathrm{~g}^{-1}$ with $92 \%$ coulombic efficiency at $0.1 \mathrm{C}$. This excellent electrochemical performance is further maintained in long cycling even at a higher C-rate (1C) and exhibits a capacity of $667 \mathrm{~mA} \mathrm{~h} \mathrm{~g}^{-1}$ after 200 cycles with coulombic efficiency $\sim 95 \%$ (an extremely slow capacity decay rate of $0.03 \%$ per cycle). Moreover, for a high-sulfur loading $\left(4.5 \mathrm{mg} \mathrm{cm}^{-2}\right)$ electrode the $\mathrm{Li}-\mathrm{S}$ battery retains $61.3 \%$ of the initial capacity after cycling for 150 cycles at $2.0 \mathrm{C}$. Further, to understand the functional mechanism of the carbon interlayer for anchoring lithium polysulfides, first principles calculations are performed based on density functional theory. To the best of our knowledge, this is the first such report on using inexpensive candle soot carbon as a cathode host and as an interlayer that results in outstanding electrochemical performance.
\end{abstract}

\section{Introduction}

Lithium-sulfur ( $\mathrm{Li}-\mathrm{S}$ ) batteries have gained a paramount position in the field of electrochemical energy storage devices in the last decade owing to their high theoretical specific energy density $\left(2600 \mathrm{~W} \mathrm{~h} \mathrm{~kg}^{-1}\right)$ and specific capacity $\left(1675 \mathrm{~mA} \mathrm{~h} \mathrm{~g}{ }^{-1}\right) \cdot{ }^{1-3}$ This is nearly five-fold higher than the commercialized lithium-ion batteries based on an intercalation mechanism, due to the redox kinetics (i.e., two-electron transfer) involved in the electrochemical reaction of lithium ions with sulfur. ${ }^{4}$ In addition, the non-toxicity and natural abundance of sulfur offer additional advantages for immense research on Li-S batteries. ${ }^{5}$ However, there are still many barriers to overcome for the fulfilment of commercial $\mathrm{Li}-\mathrm{S}$ batteries. Firstly, the insulating nature of sulfur $\left(c a .5 \times 10^{-30} \mathrm{~S} \mathrm{~cm}^{-1}\right)$ and reaction product $\mathrm{Li}_{2} \mathrm{~S}$ ( ca. $10^{-13} \mathrm{~S} \mathrm{~cm}^{-1}$ ) impedes the electronic mobility during the electrochemical reaction, resulting in sluggish reaction kinetics and low utilization of active sulfur. Secondly, the density difference between the electrochemical end product $\mathrm{Li}_{2} \mathrm{~S}$

Creative \& Advanced Research Based on Nanomaterials (CARBON) Laboratory, Department of Chemical Engineering, Indian Institute of Technology Hyderabad, Kandi-502285, Telangana, India. E-mail: cssharma@che.iith.ac.in

† Electronic supplementary information (ESI) available. See DOI: 10.1039/ d1ma00115a and sulfur (1.66 and $2.07 \mathrm{~g} \mathrm{~cm}^{-3}$, respectively) causes volume expansion in the electrode, resulting in electrode pulverization and cathode degradation leading to limited life span of the $\mathrm{Li}-\mathrm{S}$ battery. ${ }^{6,7}$ Thirdly, the dissolution of intermediate long-chain lithium polysulfides $\left(\mathrm{Li}_{2} \mathrm{~S}_{x}, 4 \leq x \leq 8\right)$ in the electrolyte, termed as "shuttle behavior", causes loss of active material (sulfur) and deposition of short-chain lithium polysulfides $\left(\mathrm{Li}_{2} \mathrm{~S}_{2} / \mathrm{Li}_{2} \mathrm{~S}\right)$ on the lithium anode surface resulting in passivation of the anode. ${ }^{6-9}$ Therefore, for achieving a suitable conducting cathode, the host material for sulfur plays an important role. Carbon is considered as a potential host for sulfur because of its electrical conductivity and feasibility to adjust the particle size, pore volume and surface area, which can help in the effective trapping of polysulfides. ${ }^{10}$ Several studies have reported that different carbon structures such as carbon nanotubes (CNTs), carbon nanofibers (CNFs), carbon nanosheets and graphene can act as a good host for sulfur. ${ }^{11-14}$ Besides, different biomass-derived carbons such as carbon derived from yeast, ${ }^{15}$ coconut shell, ${ }^{16}$ cherry pit, ${ }^{17}$ egg shell, ${ }^{18}$ silk cocoon, ${ }^{19}$ luffa sponge, ${ }^{20}$ banana peel, ${ }^{21}$ bamboo char $^{22}$ and rice popcorn ${ }^{23}$ have also been reported to be efficient hosts from the perspective of being cost effective, environmentally friendly and naturally abundant.

Another important concern for Li-S batteries is the trapping of soluble long-chain lithium polysulfides to retain the battery 
cycle life without capacity fading. Manthiram et $a .^{24}$ introduced the concept of an interlayer, a physical barricade between the cathode and the separator, to inhibit the movement of long-chain (higher order) lithium polysulfides from the cathode to the electrolyte. Moreover, the interlayer provides an alternative site for the adsorption of long-chain lithium polysulfides via physisorption or chemisorption, preventing the loss of active material (sulfur). Therefore, the cell can be operated for a long cycle life without capacity loss. ${ }^{20}$ The pioneering work by X. Gao et al. $^{25-28}$ shed light on the use of carbon materials with various strategies for enhancing the electrochemical performance. The group has reported the use of a multifunctional globular polypyrrole interlayer ${ }^{27}$ as a polysulfide blockade, which showed impressive electrochemical performance with $74 \%$ capacity retention on cycling at $0.5 \mathrm{C}$. In the following work by the group, ${ }^{28}$ they designed a porous hollow carbon aerogel using $\mathrm{CaCO}_{3}$ as a template and investigated the same as a cathode for $\mathrm{Li}-\mathrm{S}$ batteries. The as prepared cathode exhibited excellent cycling with $60.5 \%$ capacity retention at $0.1 \mathrm{C}$ with a sulfur loading of $2.2 \mathrm{mg} \mathrm{cm}^{-2}$. Moreover, the promising results reported by several research groups ${ }^{29-31}$ emphasize that interlayer modification of $\mathrm{Li}-\mathrm{S}$ batteries is a viable and efficient design method to block long-chain lithium polysulfide shuttling.

Herein, our approach is to create a conducting host as well as an inbuilt interlayer (as a polysulfide blockade) from the same source of carbon for enhanced interfacing between the electrode and interlayer. For this purpose, we chose an inexpensive combustion byproduct, candle soot, to play the dual role of an electrode inbuilt interlayer and a conducting host. The importance of this work lies in the development of an inbuilt candle soot interlayer over a candle soot-sulfur composite (SC) which can act as an excellent adhesive interlayer to the cathode and also nullify the polysulfide shuttling to a large extent. The enhancement of the capacity and cycle life with the candle soot interlayer is further verified by the electrochemical performances using cells with the interlayer (C-SC) and without the interlayer (SC). The candle soot interlayer showed improvement in the capacity and cycle life. SC delivered a capacity of $874 \mathrm{~mA} \mathrm{~h} \mathrm{~g}^{-1}$ at $0.1 \mathrm{C}$ which reduced to $193 \mathrm{~mA} \mathrm{~h} \mathrm{~g}^{-1}$ at a current rate of $6.0 \mathrm{C}$, whereas C-SC exhibited an impressive reversible capacity of 1182 and $486 \mathrm{~mA} \mathrm{~h} \mathrm{~g}^{-1}$ at current rates of 0.1 and $6.0 \mathrm{C}$, respectively. Moreover, C-SC retained a capacity of $710 \mathrm{~mA} \mathrm{~h} \mathrm{~g}^{-1}$ at $1.0 \mathrm{C}$ with $94 \%$ capacity retention over 200 cycles due to the inbuilt interlayer over the electrode, which provides alternative sites for the adsorption of long-chain lithium polysulfides. Later, the electrochemical performance was studied with SC and C-SC high-sulfur loading $\left(4.5 \mathrm{mg} \mathrm{cm}{ }^{-2}\right)$ electrodes. During long-term cyclic stability testing, C-SC was able to retain $61.3 \%$ of the initial capacity after 150 cycles at $2.0 \mathrm{C}$, while SC was able to retain only $16.9 \%$ of the initial capacity, reflecting the potential of the inbuilt interlayer. Furthermore, the experimental results were supported with first principles simulation studies, allowing in-depth understanding of the adsorption of higher order polysulfides over the carbonbased candle soot material.

\section{Experimental section}

\subsection{Preparation of sulfur-incorporated candle soot (SC)}

First, the candle soot was collected from the tip of a stable candle flame. ${ }^{32}$ It was preferably collected from the tip of the flame (Fig. S1, ESI $\dagger$ ) to avoid unburnt hydrocarbons which can reduce the electrical conductivity of the collected soot. The collected soot was ground with sulfur powder using a mortar and pestle in a mass ratio of $3: 7$. Furthermore, in order to incorporate sulfur in the carbon matrix, a melt diffusion strategy was employed. The ground mixture was kept in a tubular furnace at $155{ }^{\circ} \mathrm{C}$ for $15 \mathrm{~h}$ to enable sulfur impregnation in the carbon framework under an argon atmosphere. The furnace was then allowed to cool down to room temperature naturally and the sample was collected and labelled as sulfur incorporated candle soot (SC).

\subsection{Sulfur-incorporated candle soot with an inbuilt interlayer (C-SC)}

Sulfur-incorporated candle soot (SC) was mixed with carbon black and polyvinyl difluoride (PVDF) binder in a weight ratio of 75:10:15 using $N$-methyl-2-pyrrolidinone (NMP) as a dispersant. The resulting slurry was coated on a stainless steel (SS) current collector (diameter - $15 \mathrm{~mm}$; corresponding surface area of $1.77 \mathrm{~cm}^{-2}$ ) followed by vacuum drying for $12 \mathrm{~h}$ in an oven maintained at $80{ }^{\circ} \mathrm{C}$. The sulfur loading in each electrode

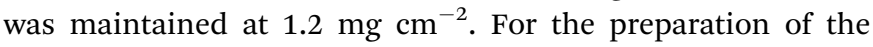
interlayer, the collected soot was dispersed in ethanol and bath sonicated for $30 \mathrm{~min}$ for uniform dispersion. Later on, a solution casting approach was adopted to spread on the SC cathode and it was vacuum dried at $80{ }^{\circ} \mathrm{C}$ for $12 \mathrm{~h}$. The loading of candle soot over the electrode was calculated to be $0.5 \mathrm{mg}$. After carbon coating, the electrode was labelled as candle soot inbuilt interlayer sulfur-incorporated candle soot (C-SC). The detailed experimental procedure to design the SC and C-SC electrodes has been illustrated in Scheme 1.

\subsection{Material characterization}

Candle soot, SC and C-SC were investigated structurally using a PANalytical X-ray diffractometer (XRD) equipped with $\mathrm{Cu}-\mathrm{K} \alpha$ radiation as an $\mathrm{X}$-ray source in a $2 \theta$ range of $5-75^{\circ}$. The Raman spectrum was recorded using a Bruker Raman microscope spectrometer equipped with a $532 \mathrm{~nm}$ laser. The $\mathrm{N}_{2}$-sorption isotherm, pore volume and pore size distribution were recorded using a Micromeritics ASAP 2020 surface area and porosity analyzer. Later, the multi-point Brunauer-Emmett-Teller (BET) equation was used to calculate the specific surface area. The surface morphology was examined using a tabletop scanning electron microscope (SEM) (make: Phenom World; model: Pro X). To quantify the amount of sulfur in the composite, thermogravimetric analysis (TGA) was performed using a PerkinElmer Pyris 1 from room temperature to $900{ }^{\circ} \mathrm{C}$.

\subsection{Electrochemical measurements}

Coin cells 2032 were assembled in a glove box maintained under an argon atmosphere $\left(\mathrm{O}_{2}<0.1 \mathrm{ppm} ; \mathrm{H}_{2} \mathrm{O}<0.1 \mathrm{ppm}\right)$. 


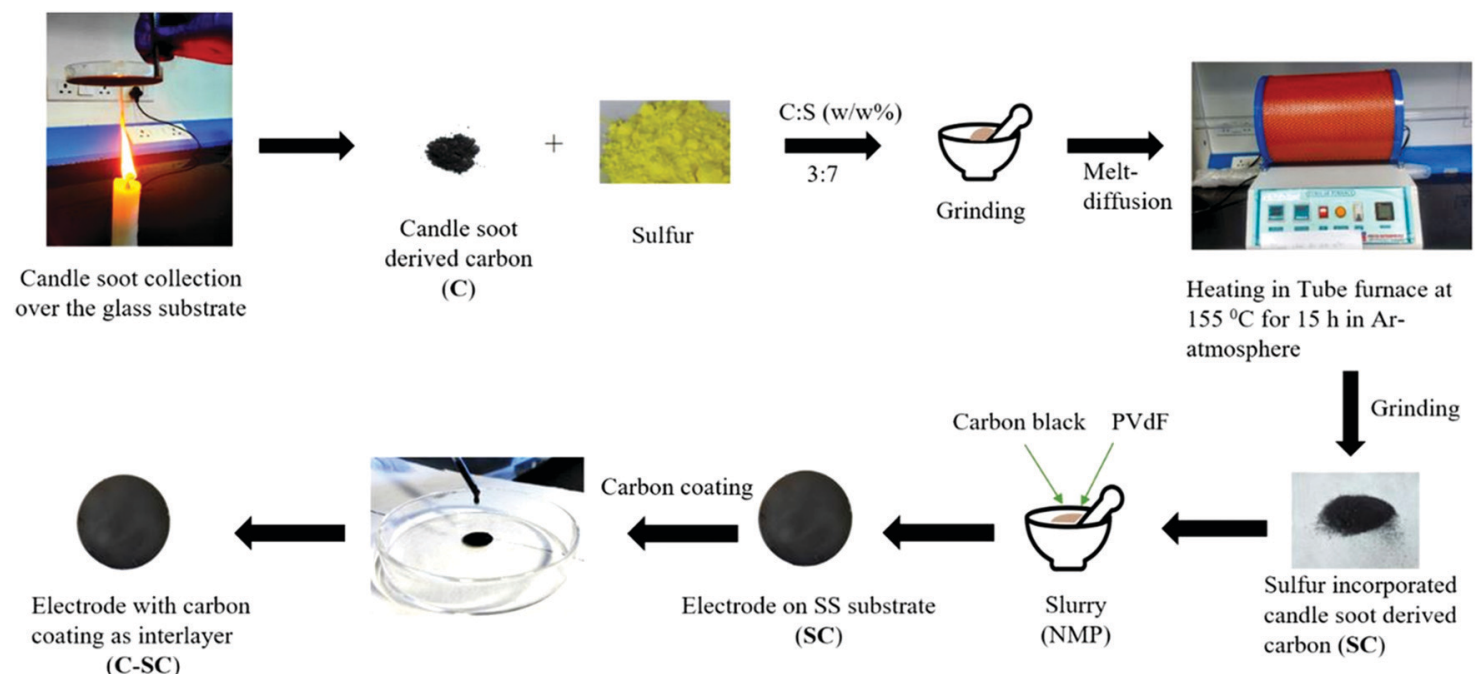

Scheme 1 Detailed experimental procedure to design the SC and C-SC electrodes.

In the assembly, the SC and C-SC electrodes were used as the cathode, lithium foil (diameter - $15 \mathrm{~mm}$ ) as the counter/ reference electrode, and glass microfiber (diameter - $19 \mathrm{~mm}$ ) as a separator. $1.0 \mathrm{M}$ lithium bis-(trifluoromethanesulfonyl) imide (LiTFSI) salt dissolved in a solvent mixture of dimethoxyethane (DME) and 1,3-dioxolane (DOL) (1:1 v/v) containing $0.1 \mathrm{M} \mathrm{LiNO}_{3}$ as an additive was prepared and used as an electrolyte. The electrolyte volume between the different cathodes and the lithium anode was controlled to about $60 \mu \mathrm{L}$. Galvanostatic charge-discharge measurements were performed using a Biologic VSP 300 in the potential range of 1.7-3.0 V (vs. $\mathrm{Li} / \mathrm{Li}^{+}$). The cyclic voltammogram (CV) measurement was carried out in a potential window of $1.7-3.0 \mathrm{~V}\left(v s . \mathrm{Li} / \mathrm{Li}^{+}\right)$at a scan rate of $0.1 \mathrm{mV} \mathrm{s}^{-1}$. Electrochemical impedance spectroscopy (EIS) was conducted using a Biologic VSP 300 electrochemical workstation in the frequency range of $0.01 \mathrm{~Hz}$ to $1 \mathrm{MHz}$ at room temperature.

\subsection{Computational method}

The optimization of all the structures was carried out with the basis set of STO-3G and the B3LYP level of theory, as reported in previous work, ${ }^{33-38}$ using the Gaussian 09 software package. The total binding energy of the systems was calculated using the following equation: $E_{\mathrm{BE}}=E_{\mathrm{C}-\mathrm{Li}_{2} \mathrm{~S}_{x}}-\left(E_{\mathrm{C}}+E_{\mathrm{Li}_{2} \mathrm{~S}_{x}}\right)$, where $E_{\mathrm{BE}}$ represents the total binding energy between carbon and polysulfide species $\mathrm{Li}_{2} \mathrm{~S}_{x}(x=4,6,8) . E_{\mathrm{C}-\mathrm{Li}_{2} \mathrm{~S}_{x}}, E_{\mathrm{Li}_{2} \mathrm{~S}_{x}}$ and $E_{\mathrm{C}}$ are the energies of polysulfides with carbon $\left(\mathrm{C}-\mathrm{Li}_{2} \mathrm{~S}_{\mathrm{n}}\right)$, long-chain lithium polysulfides $\left(\mathrm{Li}_{2} \mathrm{~S}_{x}\right)$ and carbon (C), respectively.

\section{Results and discussion}

The surface morphologies of the sulfur-incorporated candle soot (SC) electrode and candle soot inbuilt interlayer on SC (C-SC) are depicted in the SEM images shown in Fig. 1(a) and (b), respectively, and also in Fig. S2(a) and (b) (ESI $\dagger$ ). The SC electrode showed a non-uniform surface having troughs formed by agglomerates of sulfur during the melt-diffusion process as shown in Fig. 1(a). It clearly showed that the drop casting method resulted in a uniform coating of candle soot over the entire electrode surface, covering even the vacant troughs, which is evident from Fig. 1(b). Further, EDAX analysis (Fig. S2(c) and (d), ESI $\dagger$ ) suggested an increase in the carbon content on the surface of the C-SC electrode as compared to the SC electrode, further confirming the uniform coating of candle soot over the electrode. The nature of the incorporated sulfur in the carbon matrix is scrutinized through the XRD pattern. Fig. 1(c) shows the XRD pattern of sulfur, candle soot, SC, and C-SC, respectively. The broad peaks positioned at $26^{\circ}$ and $45^{\circ}$ correspond to the (002) and (101) planes, respectively, revealing the amorphous nature of the candle soot carbon. ${ }^{39,40}$ After incorporating sulfur in the candle soot carbon (SC), the crystalline peaks of sulfur became prominent, indicating the higher loading of sulfur and its existence in elemental form in the carbon matrix. In the case of C-SC, the intensity of the sulfur peaks was considerably low when compared to SC. This is due to the presence of the candle soot inbuilt interlayer on top of the electrode. This layer was found to be significant in suppressing the shuttling of polysulfides while cycling the cell, as revealed later in the study. Raman spectroscopy analysis was carried out to investigate the nature of carbon present in the collected candle soot carbon and SC in the range of $500-3500 \mathrm{~cm}^{-1}$, as depicted in Fig. 1(d). The three bands located at 1346, 1584 and $2834 \mathrm{~cm}^{-1}$ are assigned to the D-band ( $\mathrm{sp}^{3}$ carbon), G-band ( $\mathrm{sp}^{2}$ carbon) and 2D-band, respectively. The D-band is due to disorder in the carbon structure, whereas the G-band is associated with graphitic structure. ${ }^{32,41-43}$ The $I_{\mathrm{D}} / I_{\mathrm{G}}$ ratio provides information regarding the degree of disorder and it was found to be 1.00 and 1.05 for candle soot and SC, respectively, after Lorentz fitting. These results also indicated that the incorporated sulfur was in elemental form in SC without distorting the carbon matrix.

Furthermore, BET surface analysis is performed to confirm the sulfur incorporation inside the carbon host by analyzing the 
(a)

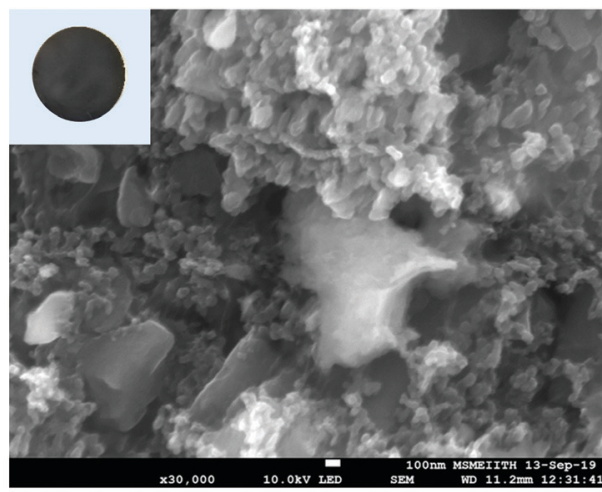

(c)

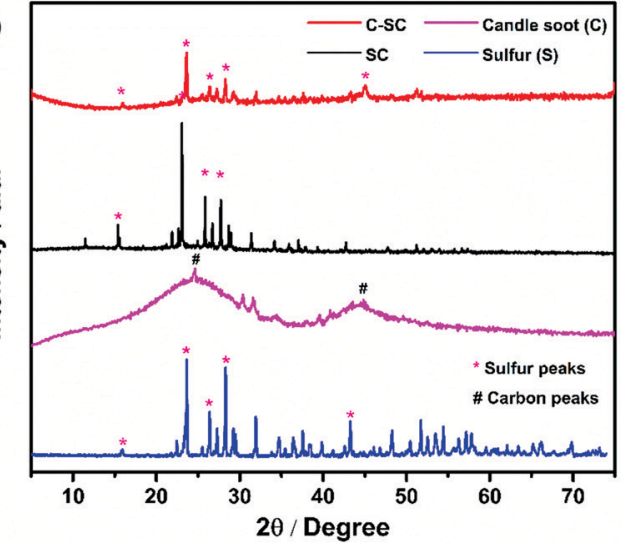

(b)

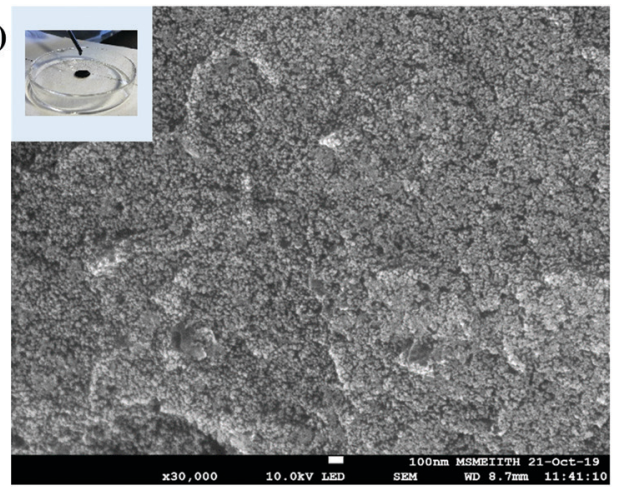

(d)

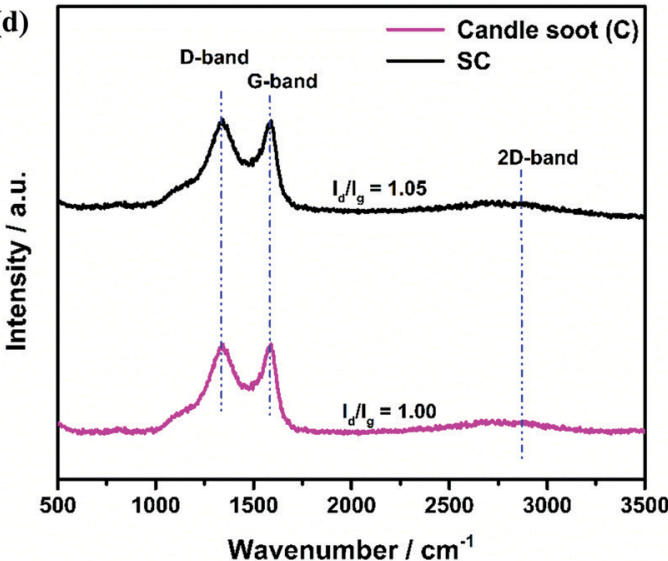

Fig. 1 Scanning electron microscope image of (a) SC and (b) C-SC; (c) X-ray diffraction pattern of sulfur, candle soot, SC and C-SC in the scanning range $5^{\circ}$ to $75^{\circ}$ and (d) Raman spectra of candle soot and SC.

changes in the surface area, pore volume and pore size of candle soot and SC. The $\mathrm{N}_{2}$ sorption isotherm (Fig. 2(a) and (b)) shows type III hysteresis loops for both the samples, revealing unrestricted monolayer formation during the adsorption and desorption process. ${ }^{44}$ The specific surface area, pore volume and average pore size of candle soot were found to be $341 \mathrm{~m}^{2} \mathrm{~g}^{-1}, 0.872 \mathrm{~cm}^{3} \mathrm{~g}^{-1}$ and $5.92 \mathrm{~nm}$, respectively. The specific surface area and pore volume of SC decreased to $12 \mathrm{~m}^{2} \mathrm{~g}^{-1}$ and $0.092 \mathrm{~cm}^{3} \mathrm{~g}^{-1}$, respectively, and the average pore size increased to $30.41 \mathrm{~nm}$, clearly indicating the successful incorporation of sulfur in the carbon pores after the melt diffusion process.

To calculate the sulfur content in the candle soot-sulfur composites, TGA of candle soot and SC was carried out in a nitrogen atmosphere at a ramp rate of $10{ }^{\circ} \mathrm{C} \min ^{-1}$ (Fig. 2(c)). The complete weight loss of candle soot was found to be around $650{ }^{\circ} \mathrm{C}$, indicating the purity of the collected soot. SC exhibited a weight loss of $\sim 70 \mathrm{wt} \%$ at $\sim 250{ }^{\circ} \mathrm{C}$, which is ascribed to the decomposition of sulfur. The second weight loss of $30 \mathrm{wt} \%$ at $\sim 650{ }^{\circ} \mathrm{C}$ can be attributed to the decomposition of candle soot present in SC. This is in good agreement with the ratio of candle soot and sulfur employed during melt diffusion and therefore ensures the effectiveness of the synthesis approach. Later on, an adsorption test was employed to visually investigate the polysulfide adsorption capability of candle soot carbon (Fig. 2(d)). A glass vial was filled with DOL/DME solvent
$(1: 1 \mathrm{v} / \mathrm{v})$ containing polysulfides $\left(\mathrm{Li}_{2} \mathrm{~S}_{6}\right)$ followed by the addition of candle soot nanoparticles. The perturbation in the solution was observed for $48 \mathrm{~h}$. The polysulfides were completely adsorbed by the candle soot, resulting in a clear and transparent solution after $48 \mathrm{~h}$, indicating that the polysulfide diffusion can be suppressed by using candle soot as an inbuilt interlayer. This prompted us to use candle soot nanoparticles as a sulfur host to prepare a cathode as well as an interlayer, and to further investigate its electrochemical performance in Li-S batteries.

The redox reaction of sulfur in SC and C-SC was investigated through cyclic voltammetry (CV) in the potential window of 1.7 to $3 \mathrm{~V}$ (Fig. 3(a)). In the cathodic scan, the peak located at $\sim 2.4 \mathrm{~V}$ corresponds to reduction of elemental sulfur, which results in formation of long-chain lithium polysulfides $\left(\operatorname{Li}_{2} \mathrm{~S}_{x}\right.$, $4 \leq x \leq 8)$ that are soluble in the electrolyte. Another peak located at $\sim 2.0 \mathrm{~V}$ corresponds to the formation of short-chain lithium polysulfides $\left(\mathrm{Li}_{2} \mathrm{~S}_{2} / \mathrm{Li}_{2} \mathrm{~S}\right)$ which are insoluble. In the reverse anodic scan, insoluble lithium polysulfides are converted to soluble polysulfides and then oxidized back to elemental sulfur $\left(\mathrm{S}_{8}\right) .{ }^{45}$ The repeatability of the redox peak with high current in all cycles indicates the reversible lithium ion storage in sulfur (Fig. S3, ESI $\dagger$ ). ${ }^{20}$ The similarity and reproducibility of the $\mathrm{CV}$ curves of $\mathrm{C}$-SC with greater electrochemical surface area compared to the CV curve of SC demonstrate that the candle soot inbuilt interlayer allowed a stable 

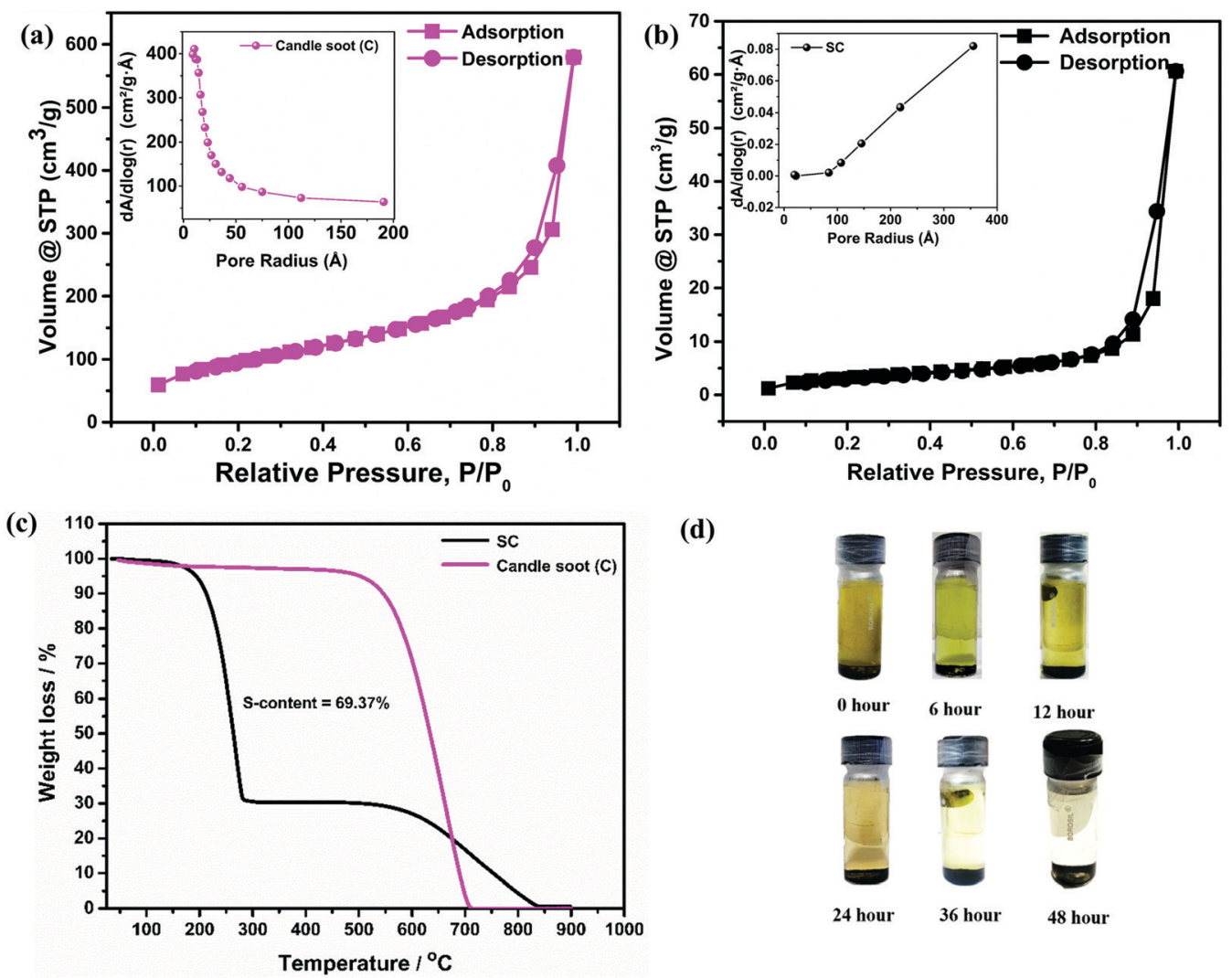

(d)

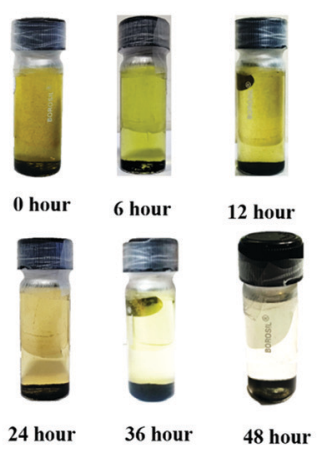

Fig. $2 \mathrm{~N}_{2}$ sorption isotherm for (a) candle soot and (b) SC (inset: corresponding pore size distribution). (c) Thermogravimetric analysis of candle soot and $\mathrm{SC}$ at a heating rate of $10{ }^{\circ} \mathrm{C} \mathrm{min}^{-1}$ in an $\mathrm{N}_{2}$ atmosphere. (d) Digital images of the glass vial with polysulfides ( $\mathrm{Li}_{2} \mathrm{~S}_{6}$ ) in DOL/DME with dissolved candle soot nanoparticles.

electrochemical reaction by nullifying the shuttle behavior, thus preventing the loss of active material. The greater electrochemical surface area with higher current in CV is an indication of the capacity enhancement. In order to further confirm that, galvanostatic charge-discharge (GCD) measurements of SC and C-SC were carried out in the potential window of 1.7 to $3 \mathrm{~V}$. Fig. 3(b) illustrates the GCD profiles of SC and C-SC carried out at a current rate of $0.2 \mathrm{C}$. The profiles exhibited two well defined plateaus during discharge which correspond to the formation of long-chain lithium polysulfides and the subsequent reduction to short-chain lithium polysulfides, while the appearance of a single plateau during charging indicates oxidation of lower order polysulfides to sulfur $\left(\mathrm{S}_{8}\right),{ }^{6,12,13}$ which are consistent with the CV studies. The initial reversible capacity of SC was found to be $665 \mathrm{~mA} \mathrm{~h} \mathrm{~g}{ }^{-1}$ with a coulombic efficiency of $86.7 \%$, whereas C-SC delivered an initial reversible capacity of $1014 \mathrm{~mA} \mathrm{~h} \mathrm{~g}^{-1}$ with a coulombic efficiency of $99.4 \%$ at $0.2 \mathrm{C}$. This capacity enhancement along with excellent coulombic efficiency highlights the role of the inbuilt candle soot interlayer in trapping the polysulfides as well as efficient utilization of the active material (sulfur).

To get insight on the enhanced electrochemical performance, electrochemical impedance spectroscopy (EIS) was performed on both the SC and C-SC electrodes (before cycling in Fig. 3(c) and after cycling in Fig. 3(d)) in the frequency range of $0.01 \mathrm{~Hz}$ to $1 \mathrm{MHz}$. Both the electrodes (SC and C-SC) follow similar trends, displaying a semi-circle in the high frequency region, which stands for the charge transfer resistance, and a nearly straight line in the low frequency region, corresponding to the lithium-ion diffusion resistance within the electrode. The smaller semicircle and Warburg line of C-SC show that the charge transfer resistance and lithium ion diffusion resistance in this electrode are minimal when compared to SC. ${ }^{46}$ This is due to the candle soot inbuilt interlayer acting as an upper current collector and providing good electrical contact with the insulating sulfur, resulting in electron mobility with less resistance.

Further, the electrochemical behaviors of the lithium sulfur battery without the interlayer (SC) and with the interlayer (C-SC) are scrutinized at various current rates. SC delivered reversible capacities of 874, 665, 508, 398, 286 and $193 \mathrm{~mA} \mathrm{~h} \mathrm{~g}^{-1}$, whereas C-SC delivered capacities of 1182, 1014, 797, 661, 529 and 486

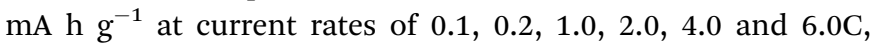
respectively (Fig. 3(e) and (f)). This capacity enhancement from 193 to $486 \mathrm{~mA} \mathrm{~h} \mathrm{~g}^{-1}$ at high current rate $6 \mathrm{C}$ substantiates the predominance of the interlayer for a faster electrochemical reaction.

Another major parameter in Li-S batteries is the capacity retention at extreme current rates (high \& low). This was evaluated by performing rate capability studies. The rate capability test will provide complete information regarding the battery storage capacity from a real application point of view 

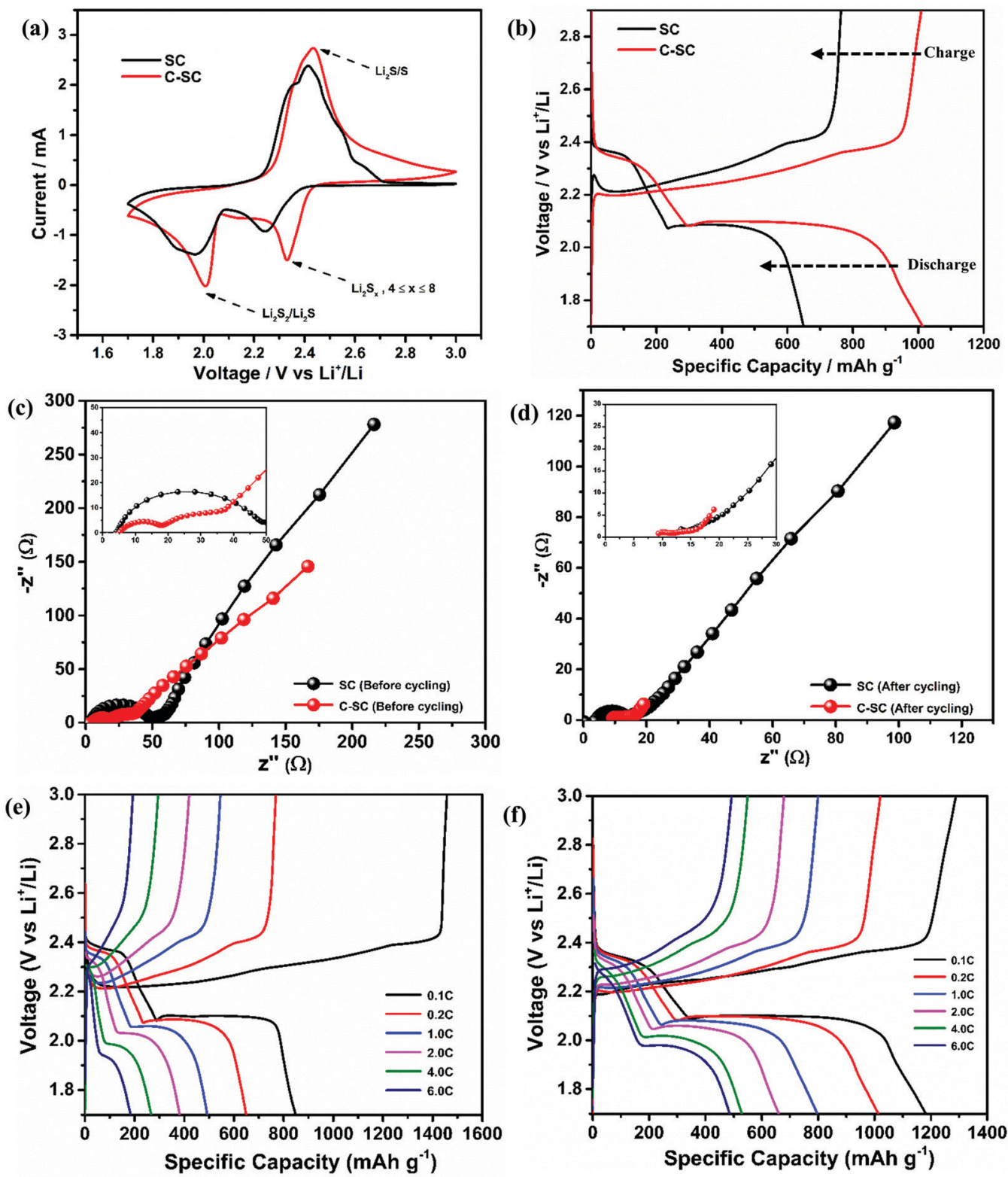

Fig. 3 (a) Cyclic voltammogram of SC and C-SC at a scan rate of $0.1 \mathrm{mV} \mathrm{s}^{-1}$. (b) Galvanostatic charge-discharge profile of SC and C-SC at a current density of $0.2 \mathrm{C}$. Nyquist plot of SC and C-SC (c) before and (d) after cycling. Galvanostatic charge-discharge profiles at various current rates for (e) SC and (f) C-SC.

(Fig. 4(a)). SC and C-SC delivered a capacity of $\sim 850 \mathrm{~mA} \mathrm{~h} \mathrm{~g}^{-1}$ and $\sim 1200 \mathrm{~mA} \mathrm{~h} \mathrm{~g}^{-1}$ at $0.1 \mathrm{C}$, respectively. It is to be noted that $\mathrm{C}$-SC retained $\sim 1200 \mathrm{~mA} \mathrm{~h} \mathrm{~g}^{-1}$ after cycling up to $6 \mathrm{C}$ when it is switched back to $0.1 \mathrm{C}$ but SC failed to retain and the capacity fell to $\sim 600 \mathrm{~mA} \mathrm{~h} \mathrm{~g}^{-1}$ (Fig. 4a). These results further prove that the candle soot inbuilt interlayer played an excellent role in blocking polysulfides and preventing their dissolution into the electrolyte. In addition, it also reveals the compatibility of the candle soot interlayer for practical usage of the battery. Even at a high current rate this interlayer showed its effective adsorption capability towards long-chain lithium polysulfides.

To quantify the cycle life, a long cycling stability test was performed on SC and C-SC at 1.0C as depicted in Fig. 4 b.
SC could retain a capacity of $382 \mathrm{~mA} \mathrm{~h} \mathrm{~g}^{-1}$ after 100 cycles with a coulombic efficiency of $88 \%$. However, when the electrode was modified with the candle soot inbuilt interlayer (C-SC), the cell exhibited an impressive capacity of $700 \mathrm{~mA} \mathrm{~h} \mathrm{~g} \mathrm{~g}^{-1}$ with $94 \%$ capacity retention even after 200 continuous charge/ discharge cycles, exhibiting an extremely low capacity decay rate of $0.03 \%$ per cycle. This further revealed the role of candle soot carbon as an inbuilt interlayer in enhancing the electrochemical performance. Later on, the cells were de-crimped post-cycling to visualize the separator condition. Digital photographs of the glass microfiber filter used as a separator for the SC and C-SC samples after cycling are presented in Fig. S4 (ESI $\dagger$ ). The separator employed with the SC electrode shows a yellowish 

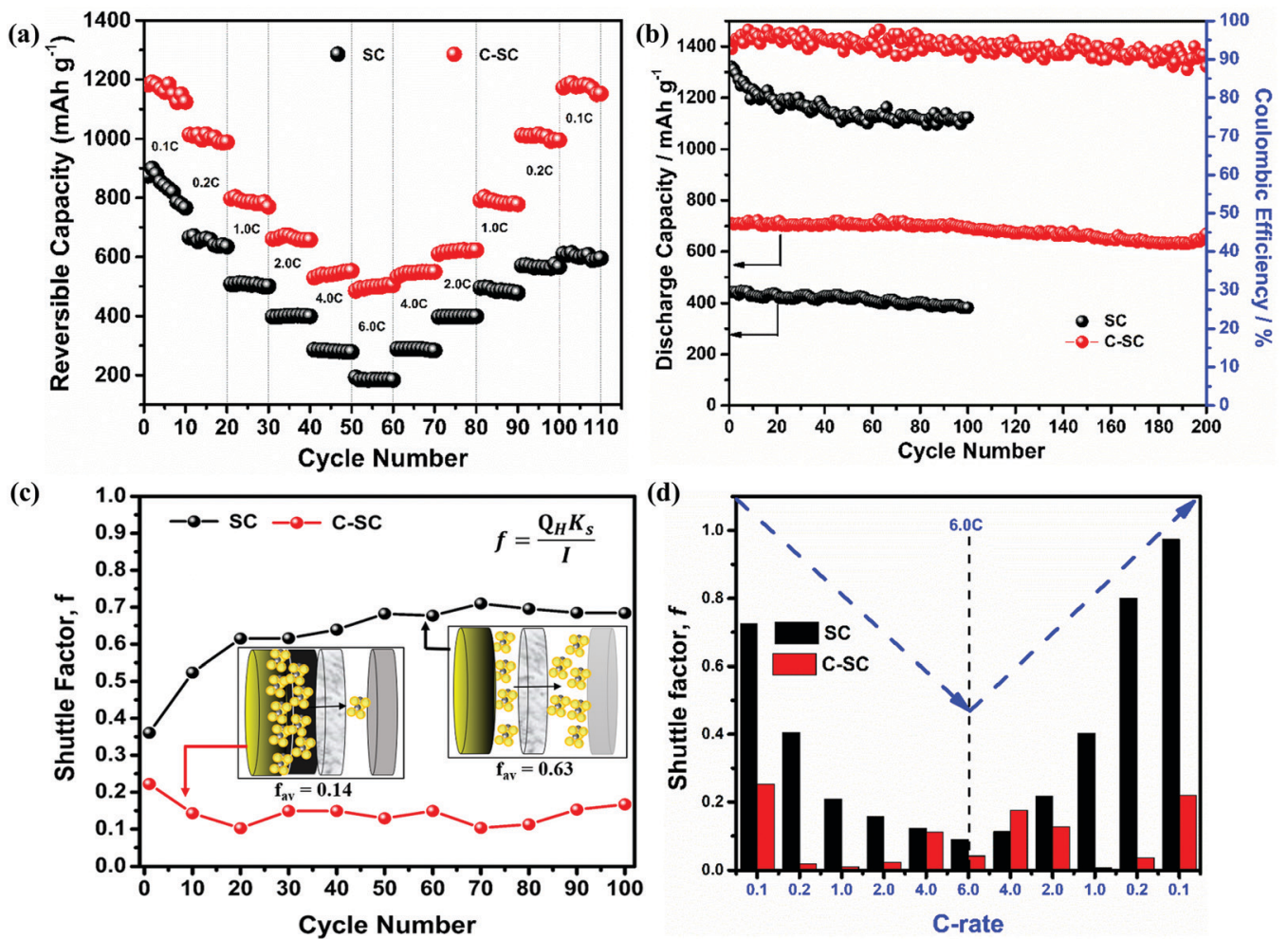

Fig. 4 (a) Rate performance of SC and C-SC at various current rates. (b) Cyclic stability of SC and C-SC at a current rate of 1.0C. Shuttle factor of SC and $\mathrm{C}-\mathrm{SC}$ for (c) the cyclic stability and (d) at various current rates.

color due to polysulfide migration through the separator. In the case of C-SC, even after 200 cycles the separator maintains its structural integrity, unlike the SC sample, which showed dark spots.

Furthermore, the shuttle factor $(f)$ was used to evaluate the extent of the shuttle effect for the SC and C-SC electrodes. The coulombic efficiency and shuttle factor are related according to the formula: ${ }^{47} C_{\text {eff }}=\frac{2 f+\log (1+f)}{2 f-\log (1-f)}$, where $C_{\text {eff }}$ is the coulombic efficiency and $f$ is the shuttle factor. The iterative calculation for the shuttle factor was carried out using the Newton-Raphson method (Matlab R2019). Fig. 4(c) depicts the plot of the shuttle factor with the cycle number (corresponding to the cyclic stability) and Fig. 4(d) depicts the plot of the shuttle factor at various current rates (corresponding to the rate performance). The SC electrode showed an increase in the shuttle factor with cycling and maintained an average shuttle factor value of 0.63 , while the C-SC electrode showed decreased shuttling and maintained a significantly low average value of 0.14 . This also indicated that there was a drastic reduction in polysulfide shuttling due to the candle soot inbuilt interlayer (Fig. 4(c)) and this was found to be consistent with the cyclic stability (Fig. 4(b)). The shuttle factor reduces with an increase in the current rate (C-rate) for C-SC as compared to SC (Fig. 4(d)). The shuttle factor study also suggested that the use of candle soot played a significant role in trapping the polysulfides within the cathode and hence prevented the loss of active material.
Meanwhile, to quantify the capability of the inbuilt interlayer, the electrochemical performance was tested using a high sulfur areal loading of $4.5 \mathrm{mg} \mathrm{cm}{ }^{-2}$ in the SC and C-SC electrodes. The CV profiles (Fig. 5(a)) of SC and C-SC revealed two peaks during the cathodic scan ascribed to long-chain lithium polysulfides followed by subsequent formation of short-chain lithium polysulfides, while one oxidation peak during the anodic scan for oxidation of short-chain polysulfides to $S_{8}$. Meanwhile, the area under the CV curve of C-SC was significantly higher, which may be related to improved charge-storage capability (Fig. 5(a)). Fig. 5(b) illustrates the GCD profiles of C-SC and SC measured at 0.1C. The discharge profile exhibited two plateaus ascribed to formation of long-chain lithium-polysulfides followed by short-chain lithiumpolysulfides. However, during charging the profile exhibited a single plateau ascribed to oxidation of short-chain lithium polysulfides to $\mathrm{S}_{8}$. The SC electrode exhibited a reversible capacity of $839 \mathrm{~mA} \mathrm{~h} \mathrm{~g}^{-1}$ with a coulombic efficiency of $58.1 \%$ while C-SC delivered a capacity of $1013 \mathrm{~mA} \mathrm{~h} \mathrm{~g}^{-1}$ with a coulombic efficiency of $98.9 \%$. The improvement in capacity can be ascribed to the nullifying effect of the inbuilt interlayer. Later, the long-term cyclic stability was tested using Li-S cells with SC and C-SC electrodes at 2C for 150 cycles (Fig. 5(c)). Interestingly, the cell with the C-SC electrode delivered excellent cycling for 150 cycles with an initial reversible capacity of $411 \mathrm{~mA} \mathrm{~h} \mathrm{~g}^{-1}$ and capacity retention of $61.3 \%$, while the cell with SC was able to retain $15.9 \%$ of the initial capacity. 
(a)

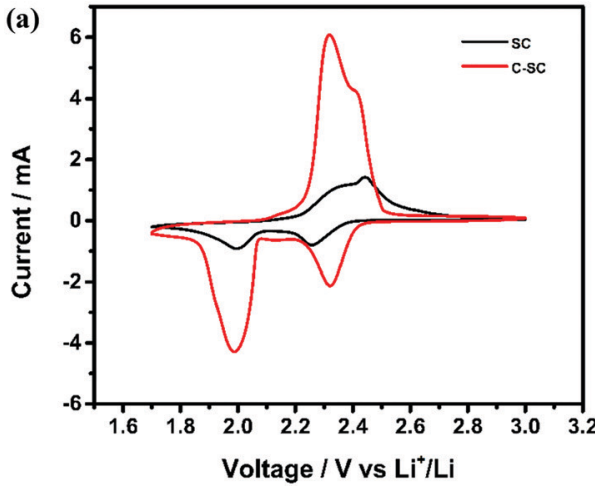

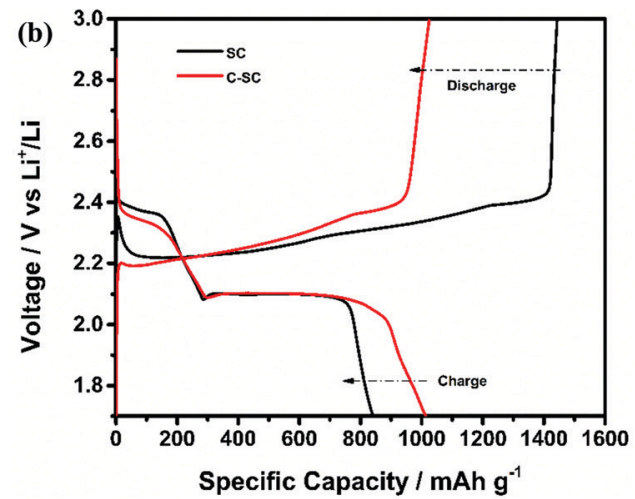

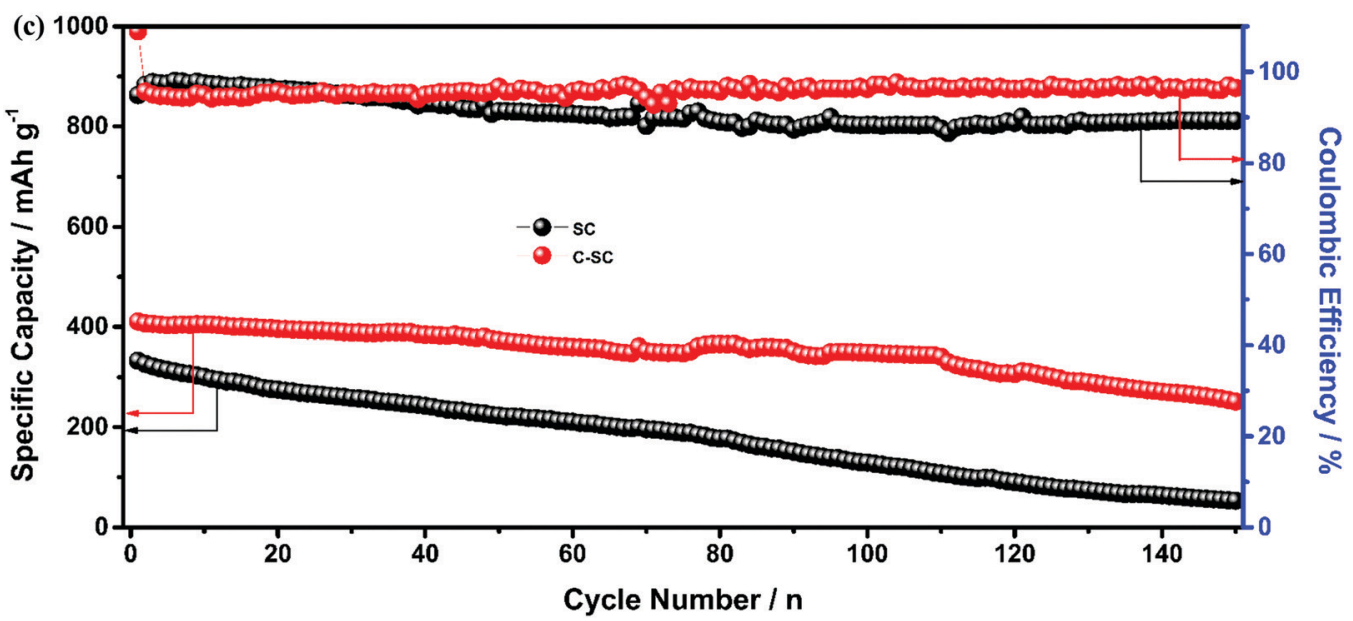

Fig. 5 Electrochemical performance with SC and C-SC high-loading sulfur electrodes. (a) Cyclic voltammogram at a scan rate of $0.1 \mathrm{mV} \mathrm{s}^{-1}$. (b) Galvanostatic charge-discharge profile at $0.1 \mathrm{C}$. (c) Long-term cyclic stability at $2 \mathrm{C}$.

In order to understand the interactions between long-chain lithium polysulfides and the candle soot inbuilt carbon interlayer (C), first-principles calculations based on density functional theory (DFT) were performed. The schematic (Fig. 6(a)) represents the binding energy calculation between polysulfide $\mathrm{Li}_{2} \mathrm{~S}_{8}$ and carbon. The binding energy of carbon with polysulfides $\mathrm{Li}_{2} \mathrm{~S}_{4}, \mathrm{Li}_{2} \mathrm{~S}_{6}$, and $\mathrm{Li}_{2} \mathrm{~S}_{8}$ is $-78.76,-52.51$, and $-26.25 \mathrm{~kJ} \mathrm{~mol}^{-1}$, respectively. Here, we observed promising results in the interaction energies of carbon with lithium polysulfides. This indicated the strong interlayer properties of the carbon-based material (candle soot) towards soluble polysulfides. The calculated result also demonstrated that the interaction between the polysulfides and carbon layer is thermodynamically favorable and more stable. Therefore, the carbon-based candle soot inbuilt interlayer not only acted as a physical trapper but also chemically anchored higher order lithium polysulfides.

Further, we investigated the possible interaction of an adsorbed polysulfide carbon layer (e.g., $\mathrm{C}-\mathrm{Li}_{2} \mathrm{~S}_{4}$ ) with other soluble polysulfides (e.g., $\mathrm{Li}_{2} \mathrm{~S}_{6}$ and $\mathrm{Li}_{2} \mathrm{~S}_{8}$ ). Fig. 6(b)-(d) represent the calculated possible interaction energies of polysulfide carbon complexes with other polysulfides and the exact possible set of reactions is shown in eqn (S1) (ESI $\dagger$ ). Three cases of interactions were considered for each polysulfide. For example, the interaction of the $\mathrm{Li}_{2} \mathrm{~S}_{4}$ polysulfide can be considered as: (i) $\mathrm{Li}_{2} \mathrm{~S}_{4}$ interaction with only the carbon layer, (ii) $\mathrm{Li}_{2} \mathrm{~S}_{4}$ polysulfide interaction with the $\mathrm{Li}_{2} \mathrm{~S}_{6}$ polysulfide adsorbed carbon layer, and (iii) $\mathrm{Li}_{2} \mathrm{~S}_{4}$ polysulfide interaction with the $\mathrm{Li}_{2} \mathrm{~S}_{8}$ polysulfide adsorbed carbon layer. Similarly, other interactions were considered for the remaining polysulfides $\mathrm{Li}_{2} \mathrm{~S}_{6}$ and $\mathrm{Li}_{2} \mathrm{~S}_{8}$.

It is interesting to note that the interaction energy of polysulfide $\mathrm{Li}_{2} \mathrm{~S}_{4}$ with the bare carbon layer is very low $\left(-78.76 \mathrm{~kJ} \mathrm{~mol}^{-1}\right)$ compared to that of the polysulfide adsorbed carbon layer $\left(-315.06\right.$ and $-262.55 \mathrm{~kJ} \mathrm{~mol}^{-1}$ for $\mathrm{C}-\mathrm{Li}_{2} \mathrm{~S}_{6}$ and $\mathrm{C}-\mathrm{Li}_{2} \mathrm{~S}_{8}$, respectively). Similar trends are observed with the other polysulfides $\left(\mathrm{Li}_{2} \mathrm{~S}_{6}\right.$ and $\left.\mathrm{Li}_{2} \mathrm{~S}_{8}\right)$. Thus, this computational study thermodynamically proved that the pristine carbon layer possessed adsorption tendencies with long-chain lithium polysulfides. However, the carbon layer with adsorbed polysulfides acted as a more effective interlayer and can further lower the extent of polysulfide shuttling in Li-S batteries.

This work demonstrates the excellent stability of the electrode in long-term cycling with interlayer modification and also stands ahead in comparison with other forms of carbon-sulfur composites and interlayer modified cells as reported previously, given in Table 1.

The improvement in the electrochemical performance is mainly attributed to the confinement of higher order 
(a)

Table 1 Different low-cost carbon precursors and interlayers for Li-S batteries

\begin{tabular}{|c|c|c|c|c|c|c|c|}
\hline Cathode & $\begin{array}{l}\text { Sulfur } \\
\text { content } \\
(\%)\end{array}$ & Interlayer & $\begin{array}{l}\text { Initial } \\
\text { capacity } \\
\left(\mathrm{mA} \mathrm{h} \mathrm{g}^{-1}\right)\end{array}$ & $\begin{array}{l}\text { Capacity } \\
\text { retention }^{a} \\
(\%)\end{array}$ & $\begin{array}{l}\text { Cycle } \\
\text { number }\end{array}$ & $\begin{array}{l}\text { C- } \\
\text { Rate }\end{array}$ & Ref. \\
\hline $\begin{array}{l}\text { rGO coated hollow yeast carbon-sulfur } \\
\text { composite }\end{array}$ & 50.3 & - & 1000 & 65 & 200 & 0.1 & 15 \\
\hline Cherry pit carbon-sulfur composite & 40.2 & - & 550 & 75 & 200 & 0.1 & 17 \\
\hline Silk cocoon carbon-sulfur composite & 48.4 & - & 1300 & 62 & 80 & 0.5 & 19 \\
\hline Hair derived carbon-sulfur composite & 69.0 & - & 1113 & 89 & 300 & 0.2 & 46 \\
\hline $\begin{array}{l}\text { Ni, S co-doped rice popcorn carbon-sulfur } \\
\text { composite }\end{array}$ & 76.1 & - & 1256 & 65 & 500 & 0.2 & 23 \\
\hline \multicolumn{8}{|l|}{ Studies with interlayer } \\
\hline Bare sulfur & 60.0 & Luffa sponge derived carbon & 1000 & 80 & 500 & 2.0 & 20 \\
\hline Bare sulfur & 70.0 & Bamboo char derived carbon & 813 & 74 & 300 & 1.0 & 22 \\
\hline Bare sulfur & 70.0 & Polyacrylonitrile spun CNF & 1134 & 41 & 200 & 0.2 & 49 \\
\hline Bare sulfur & 60.0 & $\mathrm{MoO}_{3}$ decorated CNF & 1142 & 53 & 500 & 0.2 & 50 \\
\hline
\end{tabular}

(b)

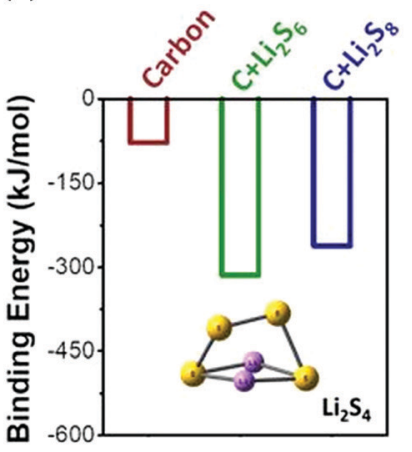

(c)

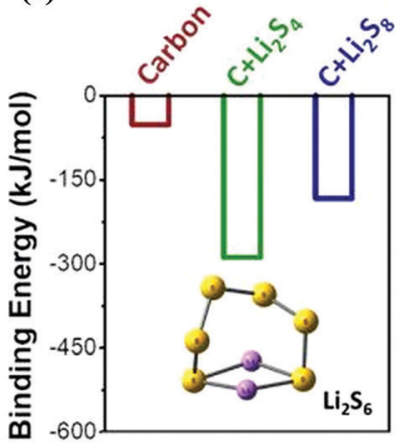

(d)

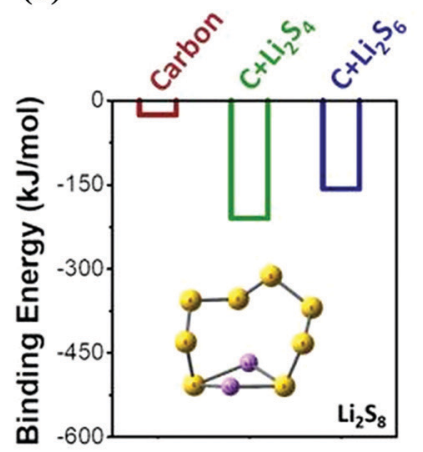

Fig. 6 (a) Schematic representation of the binding energy calculation between polysulfide $\mathrm{Li}_{2} \mathrm{~S}_{8}$ and carbon. (b) Calculated possible interaction energy of polysulfide $\mathrm{Li}_{2} \mathrm{~S}_{4}$ with carbon and other carbon adsorbed polysulfides $\left(\mathrm{Li}_{2} \mathrm{~S}_{6}\right.$ and $\mathrm{Li}_{2} \mathrm{~S}_{8}$ ). (c) Calculated possible interaction energy of polysulfide $\mathrm{Li}_{2} \mathrm{~S}_{6}$ with carbon and other carbon adsorbed polysulfides $\left(\mathrm{Li}_{2} \mathrm{~S}_{4}\right.$ and $\mathrm{Li}_{2} \mathrm{~S}_{8}$ ). (d) Calculated possible interaction energy of polysulfide $\mathrm{Li}_{2} \mathrm{~S}_{8}$ with carbon and other carbon adsorbed polysulfides $\left(\mathrm{Li}_{2} \mathrm{~S}_{4}\right.$ and $\left.\mathrm{Li}_{2} \mathrm{~S}_{6}\right)$.

polysulfides within the C-SC electrode by the development of the inbuilt candle soot interlayer which minimizes polysulfide dissolution into the electrolyte and gives effective utilization of active material (sulfur). 


\section{Conclusion}

In this article, we demonstrated an effective strategy to use candle soot carbon as an inbuilt interlayer and conducting host for a sulfur cathode. The Li-S cell with the candle soot carbon interlayer delivered a notable capacity of $1182 \mathrm{~mA} \mathrm{~h} \mathrm{~g}^{-1}$ with $92 \%$ coulombic efficiency at $0.1 \mathrm{C}$. It showed impressive long-term cyclic stability at 1C and exhibited a capacity of $667 \mathrm{~mA} \mathrm{~h} \mathrm{~g}^{-1}$ with $94 \%$ capacity retention after 200 cycles even at a high current rate of 1.0C. Further, excellent cycling was observed with highsulfur loading $\left(4.5 \mathrm{mg} \mathrm{cm}^{-2}\right)$, the electrode retaining $61.3 \%$ after 150 cycles at 2.0C. Furthermore, the candle soot interaction with polysulfides was investigated experimentally and theoretically, and it clearly showed the feasibility of candle soot carbon as a potential material to mitigate the critical issue of polysulfide shuttling in Li-S batteries. Henceforth, this study paves the way for candle soot-sulfur composite-based cathodes with a candle soot interlayer as a promising candidate for advanced eco-friendly Li-S batteries including their commercial aspects.

\section{Conflicts of interest}

The authors declare no competing financial interest.

\section{Acknowledgements}

The authors acknowledge the financial support received from the Ministry of Human Resources Development and Department of Heavy Industries, Govt. of India, under the IMPRINT scheme (Project No. 7035).

\section{References}

1 H. Zhang, W. Zhao, M. Zou, Y. Wang, Y. Chen, L. Xu, H. Wu and A. Cao, Adv. Energy Mater., 2018, 8, 1-11.

2 C. Dillard, S. H. Chung, A. Singh, A. Manthiram and V. Kalra, Mater. Today Energy, 2018, 9, 336-344.

3 K. Xie, Y. Han, W. Wei, H. Yu, C. Zhang, J. G. Wang, W. Lu and B. Wei, RSC Adv., 2015, 5, 77348-77353.

4 A. Manthiram, Y. Fu, S. H. Chung, C. Zu and Y. S. Su, Chem. Rev., 2014, 114, 11751-11787.

5 X. Zhou, X. Lu, Z. Zhang, H. Lu and Z. Lei, Diamond Relat. Mater., 2018, 85, 104-111.

6 J. Ren, L. Xia, Y. Zhou, Q. Zheng, J. Liao and D. Lin, Carbon, 2018, 140, 30-40.

7 C. Wang, X. Wang, Y. Yang, A. Kushima, J. Chen, Y. Huang and J. Li, Nano Lett., 2015, 15, 1796-1802.

8 S. Imtiaz, J. Zhang, Z. A. Zafar, S. Ji, T. Huang, J. A. Anderson, Z. Zhang and Y. Huang, Sci. China Mater., 2016, 59, 389-407.

9 D. Gueon, J. T. Hwang, S. B. Yang, E. Cho, K. Sohn, D. K. Yang and J. H. Moon, ACS Nano, 2018, 12, 226-233.

10 T. Liu, X. Sun, S. Sun, Q. Niu, H. Liu, W. Song, F. Cao, X. Li, T. Ohsaka and J. Wu, Electrochim. Acta, 2019, 295, 684-692.

11 J. Zhou, X. Liu, J. Zhou, H. Zhao, N. Lin, L. Zhu, Y. Zhu, G. Wang and Y. Qian, Nanoscale Horiz., 2019, 4, 182-189.
12 Y. Yang, S. Wang, L. Zhang, Y. Deng, H. Xu, X. Qin and G. Chen, Chem. Eng. J., 2019, 369, 77-86.

13 J. He, G. Hartmann, M. Lee, G. S. Hwang, Y. Chen and A. Manthiram, Energy Environ. Sci., 2019, 12, 344-350.

$14 \mathrm{X} . \mathrm{Xu}, \mathrm{J}$. Ruan, Y. Pang, T. Yuan and S. Zheng, RSC Adv., 2018, 8, 5298-5305.

15 Y. Li, Y. Cai, Z. Cai, J. Xu, J. Sonamuthu, G. Zhu, J. Militky, W. Jin and J. Yao, Electrochim. Acta, 2018, 285, 317-325.

16 M. Liu, Y. Chen, K. Chen, N. Zhang, X. Zhao, F. Zhao, Z. Dou, X. He and L. Wang, BioResources, 2015, 10, 155-168.

17 C. Hernández-Rentero, R. Córdoba, N. Moreno, A. Caballero, J. Morales, M. Olivares-Marín and V. Gómez-Serrano, Nano Res., 2018, 11, 89-100.

18 S. H. Chung and A. Manthiram, Adv. Mater., 2014, 26, 1360-1365.

19 B. Zhang, M. Xiao, S. Wang, D. Han, S. Song, G. Chen and Y. Meng, ACS Appl. Mater. Interfaces, 2014, 6, 13174-13182.

20 J. Yang, F. Chen, C. Li, T. Bai, B. Long and X. Zhou, J. Mater. Chem. A, 2016, 4, 14324-14333.

21 Y. Yan, Y. Wei, Q. Li, M. Shi, C. Zhao, L. Chen, C. Fan, R. Yang and Y. Xu, J. Mater. Sci.: Mater. Electron., 2018, 29, 11325-11335.

22 X. Gu, C. Lai, F. Liu, W. Yang, Y. Hou and S. Zhang, J. Mater. Chem. A, 2015, 3, 9502-9509.

23 Y. Zhong, X. Xia, S. Deng, J. Zhan, R. Fang, Y. Xia, X. Wang, Q. Zhang and J. Tu, Adv. Energy Mater., 2018, 8, 1-8.

24 Y. S. Su and A. Manthiram, Nat. Commun., 2012, 3, 1-6.

25 Y. Huang, X. Gao, X. Han, Z. Guang and X. Li, Solid State Ionics, 2020, 347, 115248.

26 Y. Huang, X. Gao, Z. Zhang, S. Batool, X. Li and T. Li, ACS Sustainable Chem. Eng., 2020, 8, 15822-15833.

27 X. Gao, Y. Huang, Z. Guang and X. Li, Energy Fuels, 2020, 34, 3931-3940.

28 X. Gao, Y. Huang, H. Gao, S. Batool, M. Lu, X. Li and Y. Zhang, J. Alloys Compd., 2020, 834, 155190.

29 B. Zheng, N. Li, J. Yang and J. Xi, Chem. Commun., 2019, 55, 2289-2292.

30 J. L. Qin, B. Q. Li, J. Q. Huang, L. Kong, X. Chen, H. J. Peng, J. Xie, R. Liu and Q. Zhang, Mater. Chem. Front., 2019, 3, 615-619.

31 J. Liu, M. Li, X. Zhang, Q. Zhang, J. Yan and Y. Wu, Phys. Chem. Chem. Phys., 2019, 21, 16435-16443.

32 M. Kakunuri and C. S. Sharma, Electrochim. Acta, 2015, 180, 353-359.

33 J. D. Dill and J. A. Pople, J. Chem. Phys., 1975, 62, 2921-2923. 34 P. J. Stephens, F. J. Devlin, C. F. Chabalowski and M. J. Frisch, J. Phys. Chem., 1994, 98, 11623-11627.

35 W. J. Hehre, K. Ditchfield and J. A. Pople, J. Chem. Phys., 1972, 56, 2257-2261.

36 A. D. Becke, J. Chem. Phys., 1993, 98, 5648-5652.

37 M. M. Francl, W. J. Pietro, W. J. Hehre, J. S. Binkley, M. S. Gordon, D. J. DeFrees and J. A. Pople, J. Chem. Phys., 1982, 77, 3654-3665.

38 Y. Fan, Z. Niu, F. Zhang, R. Zhang, Y. Zhao and G. Lu, ACS Omega, 2019, 4, 10328-10335.

39 S. Mamidi, A. Gangadharan and C. S. Sharma, Electrochim. Acta, 2019, 310, 222-229. 
40 M. Kakunuri, S. Vennamalla and C. S. Sharma, RSC Adv., 2015, 5, 4747-4753.

41 X. Ma, G. Ning, Y. Wang, X. Song, Z. Xiao, L. Hou, W. Yang, J. Gao and Y. Li, Electrochim. Acta, 2018, 269, 83-92.

42 G. Ananya, S. Raghu and S. Ramaprabhu, J. Mater. Chem. A, 2017, 5, 2784-2791.

43 M. Kakunuri, S. Kaushik, A. Saini and C. S. Sharma, Bull. Mater. Sci., 2017, 40, 435-439.

44 M. Kruk and M. Jaroniec, Chem. Mater., 2001, 13, 3169-3183.

45 S. Li, X. Chen, F. Hu, R. Zeng, Y. Huang, L. Yuan and J. Xie, Electrochim. Acta, 2019, 304, 11-19.

46 M. Yu, R. Li, Y. Tong, Y. Li, C. Li, J. D. Hong and G. Shi, J. Mater. Chem. A, 2015, 3, 9609-9615.
47 J. Q. Huang, Q. Zhang, S. M. Zhang, X. F. Liu, W. Zhu, W. Z. Qian and F. Wei, Carbon, 2013, 58, 99-106.

48 X. Long You, L. Jun Liu, M. Yuan Zhang, M. D. Walle, Y. Li and Y. N. Liu, Mater. Lett., 2018, 217, 167-170.

49 M. Yanilmaz, A. M. Asiri and X. Zhang, J. Mater. Sci., 2020, 55, 3538-3548.

50 H. Li, X. Wang, C. Qi, C. Zhao, C. Fu, L. Wang and T. Liu, Phys. Chem. Chem. Phys., 2020, 22, 2157-2163.

51 Y. Li, L. Ming, L. Jin, L. Yun and H. Jian, Mater. Res. Express, 2019, 6, 125547.

52 Y. Huang, D. Lv, Z. Zhang, Y. Ding, F. Lai, Q. Wu, H. Wang, Q. Li, Y. Cai and Z. Ma, Chem. Eng. J., 2020, 387, 124122.

53 W. Kong, L. Yan, Y. Luo, D. Wang, K. Jiang, Q. Li, S. Fan and J. Wang, Adv. Funct. Mater., 2017, 27, 1606663. 